\title{
Characterization of a Gemella-like organism isolated from an abscess of a rabbit: description of Gemella cuniculi sp. nov.
}

\author{
L. Hoyles, ${ }^{1}$ G. Foster, ${ }^{2}$ E. Falsen ${ }^{3}$ and M. D. Collins ${ }^{1}$ \\ Author for correspondence: M. D. Collins. Tel: +44 1189 357226. Fax: +44 1189267917. \\ e-mail:m.d.collins@reading.ac.uk
}

\footnotetext{
1 Department of Food Science and Technology, University of Reading, UK

2 SAC Veterinary Science Division, Drummond Hill, Inverness, UK

3 Culture Collection, Department of Clinical Bacteriology, University of Göteborg, Sweden
}

\begin{abstract}
An unknown Gram-positive, catalase-negative, ovoid-shaped bacterium isolated from the submandibular abscess of a rabbit was subjected to a polyphasic taxonomic analysis. Comparative 16S rRNA gene sequencing demonstrated the unknown coccus represents a new subline within the genus Gemella. The unknown isolate was readily distinguished from other recognized members of the genus Gemella, namely Gemella haemolysans, Gemella bergeri, Gemella morbillorum, Gemella palaticanis and Gemella sanguinis, by biochemical tests and electrophoretic analysis of whole-cell proteins. Based on both phylogenetic and phenotypic evidence, it is proposed that the unknown bacterium is classified in the genus Gemella as Gemella cuniculi sp. nov. The type strain is CCUG $\mathbf{4 2 7 2 6}^{\mathrm{T}}$.
\end{abstract}

Keywords: Gemella cuniculi sp. nov., taxonomy, phylogeny, 16S rRNA

\section{INTRODUCTION}

The genus Gemella embraces a group of catalasenegative, facultatively anaerobic, Gram-positive, coccoid-shaped (elongated and rod-shaped forms also occur) organisms which occur in pairs, tetrads or short-chains (Berger, 1992). The genus originally contained the single species Gemella haemolysans (formerly Neisseria haemolysans) and a second species, Gemella morbillorum (formerly Streptococcus morbillorum), was later assigned to the genus (Berger, 1961 ; Kilpper-Bältz \& Schleifer, 1988). Gemella haemolysans and Gemella morbillorum are commensals of the mucous membranes of humans and some warmblooded animals and have been shown to cause severe localized and generalized infections in humans, particularly immunocompromised patients (e.g. Berger, 1992; Eggelmeier et al., 1992; Kaufhold et al., 1989; Mitchell \& Teddy, 1986; Petit et al., 1993). During a study of Gemella-like organisms from human and animal sources, we recently described three other species of the genus, namely Gemella bergeri, Gemella sanguinis and Gemella palaticanis. Gemella bergeri and Gemella sanguinis were recovered from human clinical specimens (Collins et al., 1998a, b), whereas Gemella palaticanis was isolated from a $\operatorname{dog}$ (Collins et al.,

The GenBank accession number for the $16 \mathrm{~S}$ rRNA sequence of isolate CCUG $42726^{\top}$ is AJ251987.
1999). Although the pathogenic potential of these new species is not known, it seems likely that these are also residents of mucous membranes. In the course of this ongoing investigation, we have performed a polyphasic taxonomic study on a Gemella-like organism isolated from a submandibular abscess of a rabbit which does not correspond to any of the recognized species of this genus. In this article we report the phenotypic characteristics of the organism and the results of a phylogenetic analysis. Based on the results presented, a new species is described for which the name Gemella cuniculi sp. nov. is proposed.

\section{METHODS}

Culture and biochemical characterization. Strain M60449/ $99 / 1^{\mathrm{T}}$ (CCUG 42726 $)$ was isolated from a submandibular abscess of a lop-eared pet rabbit. The bacterium was recovered from a mixed infection along with Fusobacterium necrophorum, Prevotella melaninogenica and a Peptostreptococcus species. The Gemella-like isolate, CCUG $42726^{\mathrm{T}}$, was cultured in air plus $5 \% \mathrm{CO}_{2}$ on Columbia agar (Difco) supplemented with $5 \%$ horse blood at $37^{\circ} \mathrm{C}$. The strain was biochemically characterized by using the API rapid ID32 strep, API CORYNE and API ZYM systems, according to the manufacturer's instructions (API bioMérieux). Tests were performed in duplicate and the type strains of reference Gemella species, i.e. Gemella bergeri CCUG $37817^{\mathrm{T}}$, Gemella morbillorum CCUG 18164 ${ }^{\mathrm{T}}$, Gemella haemolysans CCUG $37985^{\mathrm{T}}$, Gemella palaticanis CCUG $39489^{\mathrm{T}}$ and Gemella sanguinis CCUG $27820^{\mathrm{T}}$, were included. 
PAGE analysis of whole-cell proteins. Preparation of cellular protein extracts for PAGE analysis, densitometric analysis, normalization of the protein profiles and numerical analyses were performed as described by Pot et al. (1994) using the GelCompar 3.0 software package (Applied Maths). The similarity between all pairs of traces was expressed by the Pearson product moment correlation coefficient converted for convenience to a percentage similarity value.

16S rRNA gene sequence analysis. The 16S rRNA genes of the isolate were amplified by PCR and directly sequenced using a Taq DyeDeoxy Terminator Cycle Sequencing Kit (Applied Biosystems) and an automatic DNA sequencer (model 373A, Applied Biosystems). The closest known relatives of the new isolate were determined by performing database searches. These sequences and those of other known related strains were retrieved from the GenBank or Ribosomal Database Project (RDP) Libraries and aligned with the newly determined sequence using the program CLUSTAL W (Thompson et al., 1994). The resulting multiple sequence alignment was corrected manually and a distance matrix was calculated using the programs PRETTY and DNADIST (using the Kimura two-parameter correction; Felsenstein, 1989). A phylogenetic tree was constructed according to the neighbour-joining method with the program NEIGHBOR (Felsenstein, 1989). The stability of the groupings was estimated by bootstrap analysis (500 replications) using the programs SEQBOOT, DNADIST, NEIGHBOR and CONSENSE (Felsenstein, 1989).

\section{RESULTS AND DISCUSSION}

The unidentified isolate consisted of Gram-positive, non-motile, ovoid-shaped cells. The organism grew on blood agar producing a $\beta$-haemolytic reaction and was non-pigmented. It was facultatively anaerobic and catalase-negative. Using commercially available API systems the isolate produced acid from glucose, mannitol and sorbitol. Acid production from maltose and sucrose was variable. The strain failed to produce acid from L-arabinose, D-arabitol, cyclodextrin, glycogen, lactose, methyl- $\beta$-D-glucopyranoside, melibiose, melezitose, $N$-acetylglucosamine, pullulan, trehalose, raffinose, ribose, tagatose and $\mathrm{D}$-xylose. Tests for alkaline phosphatase, acid phosphatase, ester lipase C8 (weak), phosphoamidase and pyrazinamidase (weak) were positive, whereas those for arginine dihydrolase, alanine-phenylalanine-proline arylamidase, chymotrypsin, cystine arylamidase, esterase C- $4, \alpha-$ fucosidase, $\alpha$-galactosidase, $\beta$-galacturonidase, $\alpha$-glucosidase, $\beta$-glucosidase, $\beta$-glucuronidase, lipase $\mathrm{C} 14$, $\alpha$-mannosidase, $\beta$-mannosidase, leucine arylamidase, valine arylamidase, urease and trypsin were negative. The organism did not hydrolyse aesculin or gelatin and was Voges-Proskauer-negative. In terms of its cellular morphology and overall biochemical characteristics, the unidentified bacterium resembled the genus Gemella. PAGE analysis of whole-cell protein patterns, however, clearly demonstrated the unknown coccus was phenotypically distinct from currently described members of the genus Gemella and all other reference species examined. Indeed, the unknown organism failed to display a close affinity with any of the taxa studied (Fig. 1). The nearest species to the unidentified coccus based on protein profiling was Gemella sanguinis, although the association was very loose (joining at a correlation value of less than $60 \%$ ). Other Gemella species were even more distantly related to the unknown isolate (Fig. 1). To investigate the phylogenetic position of the unknown bacterium its almost complete 16S rRNA gene sequence was determined and subjected to a comparative analysis. Sequence database searches revealed the unknown bacterium was phylogenetically most closely related to Gemella spp. (approx. 94.8-96.8\% sequence similarity). Other low-G+C-containing taxa displayed much lower levels of sequence relatedness (data not shown). A tree constructed by the neighbour-joining method depicting the phylogenetic relationships of the

Table 1. Characteristics useful in differentiating Gemella cuniculi sp. nov. from other Gemella species

- , Negative; + , positive; $v$, variable; \pm , a few strains positive.

\begin{tabular}{|c|c|c|c|c|c|c|}
\hline Test & $\begin{array}{l}\text { Gemella } \\
\text { cuniculi }\end{array}$ & $\begin{array}{c}\text { Gemella } \\
\text { bergeri }\end{array}$ & $\begin{array}{c}\text { Gemella } \\
\text { haemolysans }\end{array}$ & $\begin{array}{c}\text { Gemella } \\
\text { morbillorum }\end{array}$ & $\begin{array}{c}\text { Gemella } \\
\text { palaticanis }\end{array}$ & $\begin{array}{c}\text { Gemella } \\
\text { sanguinis }\end{array}$ \\
\hline \multicolumn{7}{|l|}{ Acid from: } \\
\hline Lactose & - & - & - & - & + & - \\
\hline Mannitol & + & - & - & $\mathrm{V}$ & - & + \\
\hline Maltose & - & - & + & + & + & + \\
\hline Sucrose & - & - & $\mathrm{V}$ & + & + & + \\
\hline Sorbitol & + & - & - & \pm & - & + \\
\hline Trehalose & - & - & - & - & + & - \\
\hline \multicolumn{7}{|l|}{ Production of: } \\
\hline Alkaline phosphatase & + & - & + & - & - & + \\
\hline Alanine-phenylalanine-proline arylamidase & - & - & - & $\mathrm{V}$ & + & + \\
\hline Glycyl-tryptophan arylamidase & - & - & $\mathrm{V}$ & $\mathrm{v}$ & + & - \\
\hline
\end{tabular}




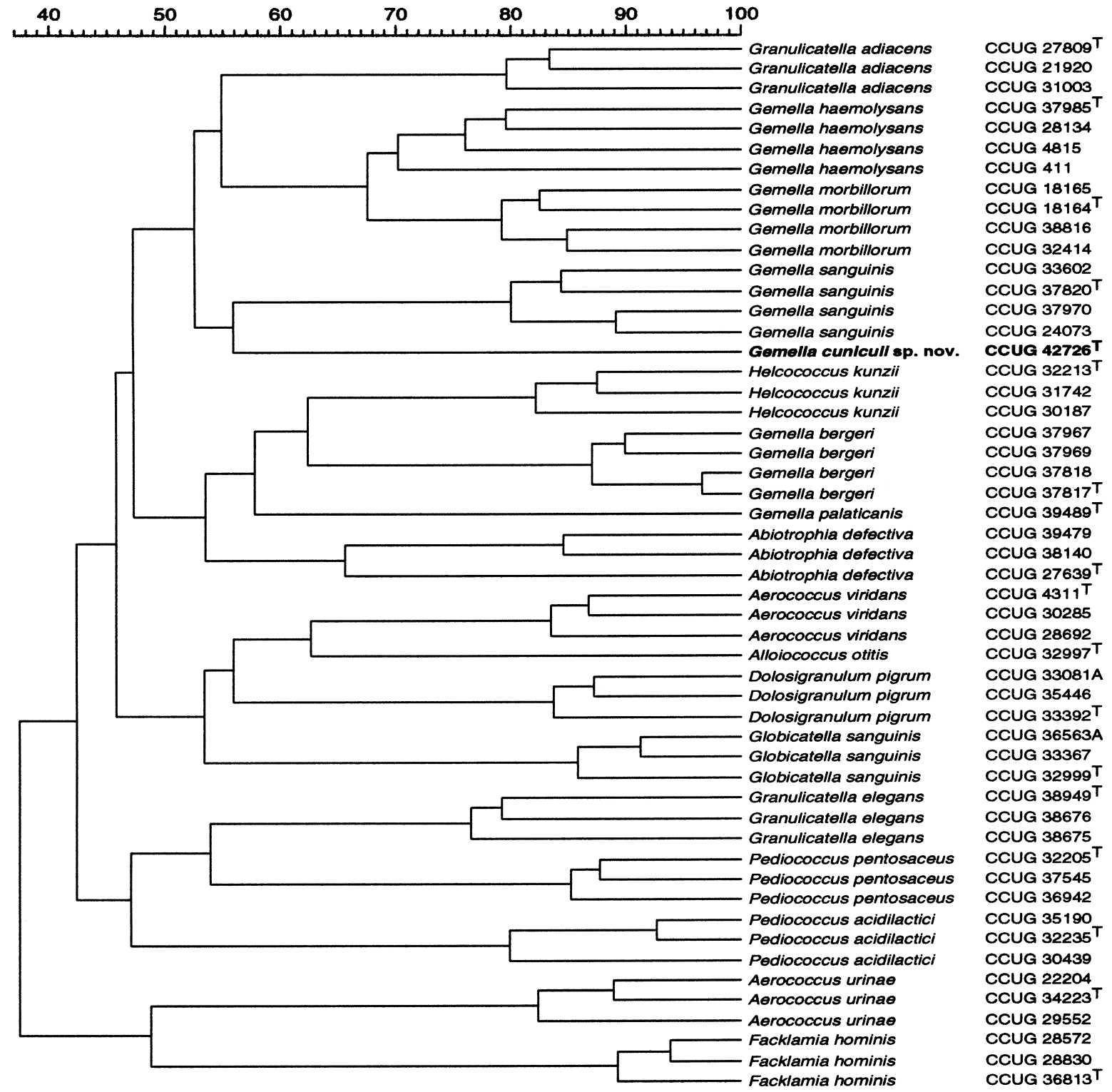

Fig. 1. Dendrogram derived from the unweighted pair group average linkage of correlation coefficients (expressed as percentage values) between whole-cell protein patterns of Gemella cuniculi sp. nov. and some relatives.

unidentified organism is shown in Fig. 2 and unequivocally demonstrates that the organism represents a new species within the genus Gemella. The bacterium formed a distinct subline and did not display a particularly significant affinity with any of the described species of the genus.

The polyphasic taxonomic analysis clearly shows the unknown ovoid-shaped bacterium isolated from a submandibular abscess of a rabbit represents a hitherto unrecognized member within the genus Gemella. Phylogenetically the bacterium forms a distinct subline clustering within the confines of the Gemella clade. 16S rRNA sequence divergence values of greater than $3 \%$ with other members of this genus unequivocally demonstrate the unknown coccus is worthy of separate species status. In addition, the unidentified coccus can be phenotypically readily distinguished from all currently described Gemella species by biochemical tests (Table 1) and whole-cell protein profiling. Therefore, based on both phylogenetic and phenotypic evidence we consider the bacterium merits classification as a new species of the genus Gemella, for which the name Gemella cuniculi sp. nov. is proposed.

\section{Description of Gemella cuniculi sp. nov.}

Gemella cuniculi (cu.ni'cu.li. L. gen. masc. n. cuniculi of the rabbit).

Cells are Gram-positive, non-motile cocci. Produces $\beta$-haemolysis on blood agar. Non-pigmented. Facul- 


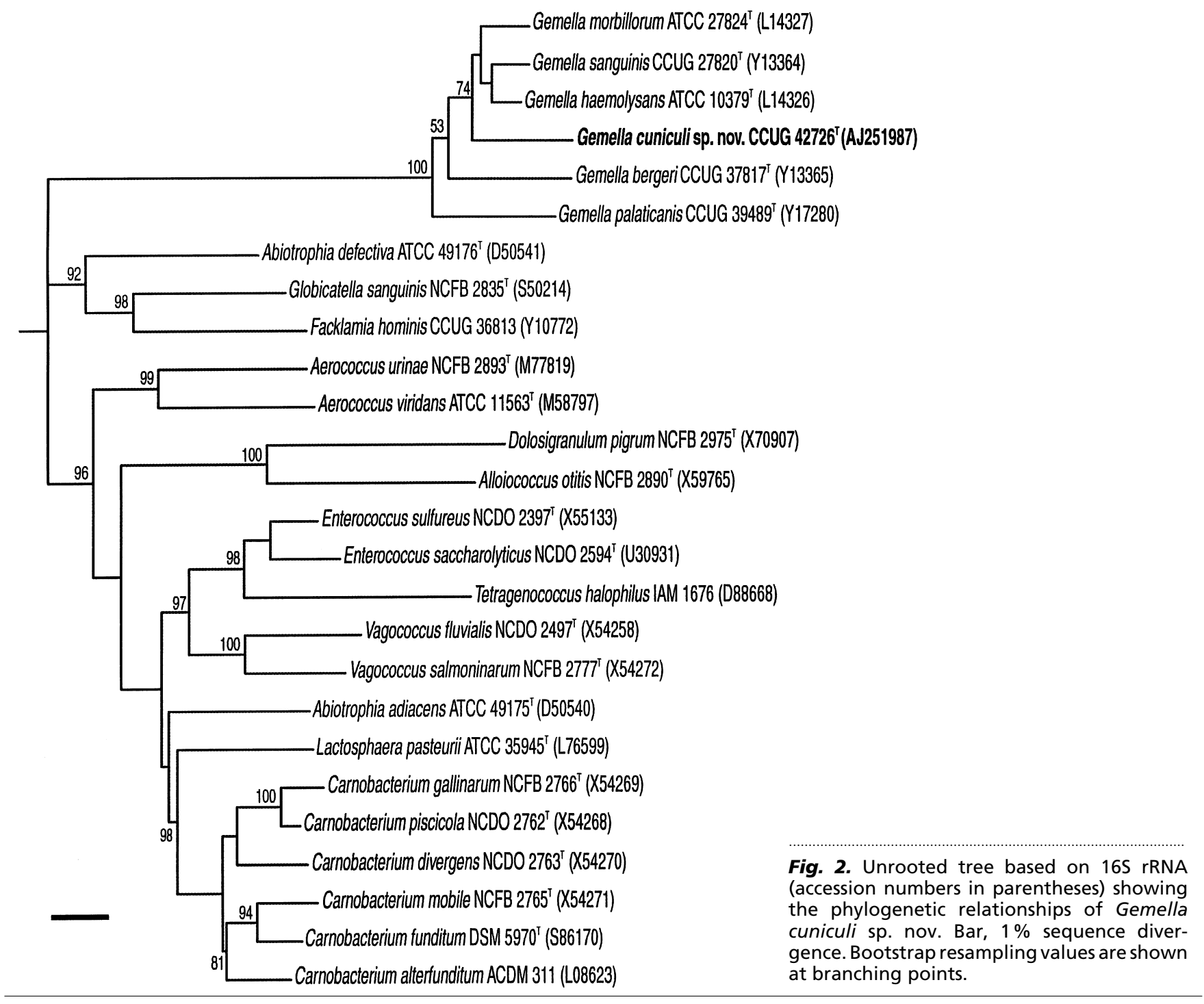

tatively anaerobic and catalase-negative. Acid is produced from glucose, mannitol and sorbitol. Acid may be produced from maltose and sucrose. Acid is not produced from L-arabinose, D-arabitol, cyclodextrin, glycogen, melibiose, melezitose, $N$-acetylglucosamine, pullulan, raffinose, ribose, tagatose or D-xylose. Acid phosphatase, alkaline phosphatase, ester lipase C8 (weak), phosphoaminidase and pyrazinamidase are produced. Alanine-phenylalanine-proline arylamidase, arginine dihydrolase, chymotrypsin, cystine arylamidase, esterase $\mathrm{C}-4, \alpha$-fucosidase, $\alpha$-galactosidase, $\quad \beta$-galacturonidase, $\alpha$-glucosidase, $\beta$ glucosidase, $\beta$-glucuronidase, $\alpha$-mannosidase, $\beta$ mannosidase, lipase $\mathrm{C} 14$, leucine arylamidase, valine arylamidase, urease and trypsin are not produced. Aesculin and gelatin are not hydrolysed and nitrate is not reduced to nitrite. Voges-Proskauer-negative. Isolated from a submandibular abscess of a rabbit. Habitat is unknown. The type strain is CCUG $42726^{\mathrm{T}}$ $\left(=\right.$ CIP $\left.106481^{\mathrm{T}}\right)$.

\section{ACKNOWLEDGEMENTS}

We are grateful to Professor Hans Trüper (University of Bonn, Germany) for help in coining the species epithet and to Lena Dahl for performing PAGE analysis.

\section{REFERENCES}

Berger, U. (1961). A proposed new genus of Gram-negative cocci: Gemella, Int Bull Nomencl Taxon 11, 17-19.

Berger, U. (1992). The genus Gemella. In The Prokaryotes, 2nd edn, pp. 1643-1653. Edited by A. Balows, H. G. Trüper, M. Dworkin, W. Harder \& K.-H. Schleifer. New York: Springer.

Collins, M. D., Hutson, R. A., Falsen, E., Sjoden, B. \& Facklam, R. R. (1998a). Gemella bergeriae sp. nov., isolated from human clinical specimens, J Clin Microbiol 36, 1290-1293.

Collins, M. D., Hutson, R. A., Falsen, E., Sjoden, B. \& Facklam, R. R. (1998b). Description of Gemella sanguinis sp. nov., isolated from human clinical specimens, J Clin Microbiol 36, 3090-3093. 
Collins, M. D., Jovita, M. R., Foster, G., Sjoden, B. \& Falsen, E. (1999). Characterisation of a Gemella-like organism from the oral cavity of a dog: description of Gemella palaticanis sp. nov, Int J Syst Bacteriol 49, 1523-1526.

Eggelmeier, F., Petit, P. \& Dijkmans, B. A. C. (1992). Total knee arthroplasty infection due to Gemella haemolysans, $\mathrm{Br} J$ Rheumatol 31, 67-69.

Felsenstein, J. (1989). PHYLIP - phylogeny inference package (version 3.2), Cladistics 5, 164-166.

Kaufhold, A., Fransen, D. \& Lutticken, R. (1989). Endocarditis caused by Gemella haemolysans, Infection 17, 385-387.

Kilpper-Bältz, R. \& Schleifer, K.-H. (1988). Transfer of Streptococcus morbillorum to the genus Gemella as Gemella morbillorum, Int J Syst Bacteriol 38, 442-443.

Mitchell, R. G. \& Teddy, P. L. (1986). Meningitis due to Gemella haemolysans after radiofrequency trigeminal rhizotomy, $J$ Clin Pathol 38, 558-560.

Petit, Y. J., Layre, J. C., Lamaury, I., Perez, C., Jonquet, Q. \& Janbon, F. (1993). Purulent-meningitis caused by Gemella haemolysans, Presse Med 22, 444.

Pot, B., Vandamme, P. \& Kersters, K. (1994). Analysis of electrophoretic whole-organism protein fingerprints. In Chemical Methods in Prokaryotic Systematics, pp. 493-521. Edited by M. Goodfellow \& A. G. O'Donnell. Chichester: Wiley.

Thompson, J. D., Higgins, D. G. \& Gibson, T. J. (1994). CLUSTAL $\mathrm{W}$ : improving the sensitivity for progressive multiple sequence alignment through sequence weighting, position-specific gap penalties and weight matrix choice, Nucleic Acids Res 22, $4673-4680$ 